\title{
RANCANG BANGUN SISTEM UNTUK MENENTUKAN TIM YANG BERMAIN DALAM PERTANDINGAN FUTSAL MENGGUNAKAN METODE REKURSIF
}

\author{
Suherman Herman ${ }^{1}$ dan lksal $^{2}$ \\ 1suherman.unsera@gmail.com, 2iksal_r@yahoo.com \\ 12 Teknik Informatika, Fakultas Teknologi Informasi, \\ Universitas Serang Raya, Banten
}

\begin{abstract}
Abstrak
Setiap dalam pertandingan futsal yang akan diselenggarakan, Panitia pertandingan sulit menentukan tim yang akan bermain secara objektif dengan menggunakan metode yang dapat digunakan untuk menentukan tim bermain secara cepat dan objektif. Dalam penentuan tim bermain futsal menjadi masalah panitia disetiap pertandingan, ketepatan panitia dalam menentukan tim bermain merupakan tuntunan setiap pemain yang akan bermain terlebih dahulu. Pada penelitian ini akan menghasilkan aplikasi untuk menentukan tim bermain secara cepat dan objektif dengan menggunakan metode rekursif sebagai metode dalam melakukan proses kemungkinan-kemungkinan tim bermain yang akan bertanding. Kemudian dengan proses random kemungkinan-kemungkinan yang muncul dari proses rekursif akan dipilih satu kemungkinan dari sekian banyak kemungkinan untuk menghasilkan tim bermain secara objektif. Dengan dukungan aplikasi ini panitia akan dapat menyelesaikan permasalahan dalam penentuan tim bermain futsal, yaitu secara cepat dan objektif.
\end{abstract}

Kata Kunci : Sistem Pendukung Keputusan, Metode Rekursif, Futsal, Random.

\section{Pendahuluan}

Menurut Lukimanto Yudianto (2009:54) " Futsal adalah permainan jenis sepakbola yang dimainkan oleh 10 orang (masing-masing 5 orang ), serta menggunakan bola lebih kecil dan lebih berat daripada yang digunakan dalam sepakbola. Pertandingan ini merupakan permainan bola yang terdiri dari dua tim dengan masing-masing anggota tim terdiri dari 5 pemain utama dan maksimal 7 orang pemain cadangan. Futsal sendiri telah diciptakan sejak tahun 1930 oleh JUAN CARLOS CERIANI di Uruguay. Hingga saat ini olah raga futsal berkembang sangat pesat bahkan telah menjadi bagian dari FIFA (Fédération Internationale de Football Association) sejak tahun 1989. Dalam beberapa tahun ini, futsal sangat marak di Indonesia. Hal ini dilihat dari banyaknya bermunculan klub-klub futsal yang memiliki banyak anggota dengan kemampuan bermain yang sama. Dengan banyaknya klub yang bermunculan ini maka sering diadakannya pertandingan atau perlombaan di bidang olahraga futsal yang selalu banyak diikuti oleh setiap klub.

Hal ini membuat panitia sering disulitkankan dalam menentukan daftar nama tim pemain yang akan bertanding terlebih dahulu, dalam penelitian ini dilakukan studi kasus pada lapangan futsal Premiere Sport Centre berdasarkan observasi dan wawancara. Premiere Sport Centre merupakan nama tempat lapangan futsal yang berada di lingkungan barokah, Dalam pertandingan futsal yang diselenggarakan di Premiere Sport Panitia pertandingan sulit menentukan tim yang akan bermain terlebih dahulu, di karenakan banyaknya tim yang akan bertanding sehingga panitia belum menentukan lawan tim lebih kecenderungan bersifat subjektif, dan selama ini panitia dalam menentukan tim bermain masih manual dengan cara masing-masing tim mengambil kertas untuk menentukan tim bermain. Untuk itu diperlukan suatu sistem pendukung keputusan yang dapat membantu panitia untuk memecahkan masalah tersebut dengan memanfaatkan data dan informasi yang telah di dapat. Informasi yang di maksud adalah namanama tim yang akan ikut bertanding. Sistem pendukung keputusan (SPK) adalah bagian dari sistem informasi berbasis komputer termasuk sistem berbasis pengetahuan atau manajemen pengetahuan yang dipakai untuk mendukung pengambilan keputusan dalam suatu organisasi atau perusahaan (Rangkuti, 2015). Tujuannya adalah untuk membantu pengambilan keputusan memilih berbagai alteratif keputusan yang merupakan hasil pengolahan informasi-informasi yang diperoleh / tersedia dengan menggunakan model-model menggunakan model-model pengambilan keputusan. Lima karakteristik utama SPK adalah 


\section{ILKOM Jurnal Ilmiah Volume 9 Nomor 3 Desember 2017}

sitem yang berbasis komputer, dipergunakan untuk mengambil keputusan, untuk memecahkan masalahmasalah yang rumit yang tidak dapat digunakan dengan kakulasi manual, melalui cara simulasi yang interaktif, komponen utamanya data dan model analisis (Sandy, 2002).

\section{Metode Penelitian}

Metode penelitian yang akan digunakan adalah sistem pendukung keputusan penentuan tim bermain pada pertandingan futsal menggunakan metode rekursif.. Metode rekursif merupakan salah satu metode yang dapat memanggil dirinya sendiri untuk melakukan proses berulang-ulang. Jika variable yang digunakan sebagai kondisi yang menghentikan rekursif tersebut berisi kondisi yang harus melakukan proses pemanggilan fungsi tersebut secara berulang-ulang tanpa henti, oleh karena itu perlu adanya random untuk menghasilkan suatu tim yang akan bermain. Maka itu peneliti dalam hal ini akan menerapkan bagaimana metode rekursif dapat digunakan dalam sistem penentuan tim bermain dalam pertandingan futsal.

\section{PENERAPAN METODE REKURSIF UNTUK TIM MAIN}

Penerapan rekursif dalam suatu pertandingan dapat dilakukan dengan cara mengfaktorialkan sebuah bilangan dengan tujuan agar proses penentun pertandingan dapat dilakukan dengan cepat dan efektif, karena dengan metode rekursif ini penentuan mudah ditentukan dengan proses input data tim bermain.

Pemanggilan dirinya sendiri (rekursif) bisa berarti proses berulang yang tidak bisa diketahui kapan berakhir sehingga dalam rekursif harus ada titik pemberhentian sebagai pengendali rekursif, adanya langkah yang menuju pada titik pemberhentian dengan menggunakan random untuk menghasilkan output tim main.

\section{PENERAPAN METODE REKURSIF}

Analisis yang dilakukan untuk menentukan tim bermain pada pertandingan futsal dengan menggunakan metode rekursif contoh dengan jumlah 12 tim main, yaitu dengan cara :

1. Menentukan jumlah tim yang terdiri dari 12 Tim yang akan bertanding, kemudian menentukan grup yaitu dengan cara membagi jumlah tim menjadi dua grup, jadi masing-masing grup terdiri dari 6 tim (syarat satu grup harus berjumlah genap tim nya).

2. Menentukan tim bermain untuk masing-masing grup dengan menggunakan proses rekursif dengan cara memfaktorialkan jumlah tim dalam setiap grup.

Misalkan user melakukan inputan angka 6 sebagai bilangan positif, maka perhitungan menjadi secara faktorial $66^{*} 4^{*} 3^{*} 2 * 1$ ! Yaitu :

$6 * 5 !=30$

$6^{\star} 5^{\star} 4 !=120$

$6 * 5^{*} 4 * 3 !=360$

$6^{*} 5^{*} 4^{*} 3^{*} 2 !=720$

$6^{*} 5^{*} 4^{*} 3^{*} 2 * 1 !=720$ kemungkinan

3. Dari 720 kemungkinan di atas di lakukan proses random untuk menentukan tim bermain futsal. Tujuannya adalah untuk menampilkan tim main dalam satu grup dengan cara objektif. Misalkan grup pertama tim bermain futsal hasil random yang tampil adalah ADBECF.

4.Dari hasil random grup pertama kemudian dibagi menjadi dua tim-dua tim, contoh hasil random grup pertama ADBECF jadi A vs $D$, $B$ vs $E$, dan $C$ vs $F$.

5.Lalu menampilkan tim bermain futsal untuk masing-masing grup sebagai acuan panitia dan peserta dalam bermain yang ditampilkan dalam bentuk laporan.

\section{Hasil dan Pembahasan}

Penerapan rekursif dalam suatu pertandingan dapat dilakukan dengan cara mengfaktorialkan sebuah bilangan dengan tujuan agar proses penentun pertandingan dapat dilakukan dengan cepat dan efektif, karena dengan metode rekursif ini penentuan mudah ditentukan dengan proses input data tim bermain. 
Pemanggilan dirinya sendiri (rekursif) bisa berarti proses berulang yang tidak bisa diketahui kapan berakhir sehingga dalam rekursif harus ada titik pemberhentian sebagai pengendali rekursif, adanya langkah yang menuju pada titik pemberhentian dengan menggunakan random untuk menghasilkan output tim main.

Analisis yang dilakukan untuk menentukan tim bermain pada pertandingan futsal dengan menggunakan metode rekursif, yaitu dengan cara :

1. Menentukan jumlah tim yang terdiri dari 12 Tim yang akan bertanding, kemudian menentukan grup yaitu dengan cara membagi jumlah tim menjadi dua grup, jadi masing-masing grup terdiri dari 6 tim ( syaratnya satu grup harus berjumlah genap tim nya).

2. Menentukan tim bermain untuk masing-masing grup dengan menggunakan proses rekursif dengan cara memfaktorialkan jumlah tim dalam setiap grup.

Misalkan user melakukan inputan angka 6 sebagai bilangan positif, maka perhitungan menjadi secara faktorial $6{ }^{*} 5^{*} 4^{*} 3^{*} 2^{*} 1$ ! Yaitu :

$6^{*} 5 !=30$

$6 * 5^{*} 4 !=120$

$6 * 5^{\star} 4 * 3 !=360$

$6^{*} 5^{*} 4^{*} 3^{*} 2 !=720$

$6 * 5^{*} 4^{*} 3^{*} 2^{*} 1 !=720$

Tabel 1. Proses perhitungan rekursif secara faktorial

\begin{tabular}{|c|c|c|}
\hline Nilai K & Proses Return & Proses Nilai Rekursif \\
\hline Inputan $\mathrm{K}=6$ & $6^{*}$ faktorial $(4-1)$ & $6^{*} ?$ \\
\hline $\mathrm{K}=(6-1)=5$ & $5^{\star}$ faktorial $(6-1)$ & $6 * 5 ?$ \\
\hline $\mathrm{K}=(5-1)=4$ & $4^{\star}$ faktorial $(6-1)$ & $6 * 5 * 4 ?$ \\
\hline$K=(4-1)=3$ & $3^{\star}$ faktorial $(3-1)$ & $6 * 5^{\star} 4 * 3 ?$ \\
\hline $\mathrm{K}=(3-1)=2$ & $2^{*}$ faktorial $(2-1)$ & $6 * 5^{\star} 4^{\star} 3^{\star} 2 ?$ \\
\hline$K=(2-1)=1$ & $1 *$ faktorial $(1-1)$ & $6 * 5^{*} 4^{*} 3^{*} 2^{*} 1 ?$ \\
\hline$K=(1-1)=0$ & 1 & $6 * 5 * 4 * 3 * 2 * 1 * 1$ \\
\hline \multicolumn{2}{|l|}{ Hasil } & 720 \\
\hline
\end{tabular}

Contoh dalam sebuah pertandingan futsal dalam setiap grup ada enam tim yang akan bertanding, maka terdapat 720 kemungkinan tim lawan yang akan bermain terlebih dahulu, berikut hasil rekursifnya :

Nama tim : A,B,C,D,E,F

Berikut hasil proses rekursifnya :

\begin{tabular}{|l|l|l|l|l|l|}
\hline \multicolumn{7}{|c}{ Tabel 2. Hasil Rekursif } \\
ABCDEF & BACDEF & CABDEF & DABCEF & EABCDF & FABCDE \\
ABCDFE & BACDFE & CABDFE & DABCFE & EABCFD & FABCED \\
ABCEDF & BACEDF & CABEDF & DABECF & EABDCF & FABDCE \\
ABCEFD & BACEFD & CABEFD & DABEFC & EABDFC & FABDEC \\
ABCFDE & BACFDE & CABFDE & DABFCE & EABFCD & FABECD \\
ABCFED & BACFED & CABFED & DABFEC & EABFDC & FABEDC \\
ABDCEF & BADCEF & CADBEF & DACBEF & EACBDF & FACBDE \\
ABDCFE & BADCFE & CADBFE & DACBFE & EACBFD & FACBED \\
ABDECF & BADECF & CADEBF & DACEBF & EACDBF & FACDBE \\
ABDEFC & BADEFC & CADEFB & DACEFB & EACDFB & FACDEB \\
ABDFCE & BADFCE & CADFBE & DACFBE & EACFBD & FACEBD \\
ABDFEC & BADFEC & CADFEB & DACFEB & EACFDB & FACEDB \\
ABECDF & BAECDF & CAEBDF & DAEBCF & EADBCF & FADBCE \\
ABECFD & BAECFD & CAEBFD & DAEBFC & EADBFC & FADBEC \\
\hline
\end{tabular}


ILKOM Jurnal Ilmiah Volume 9 Nomor 3 Desember 2017

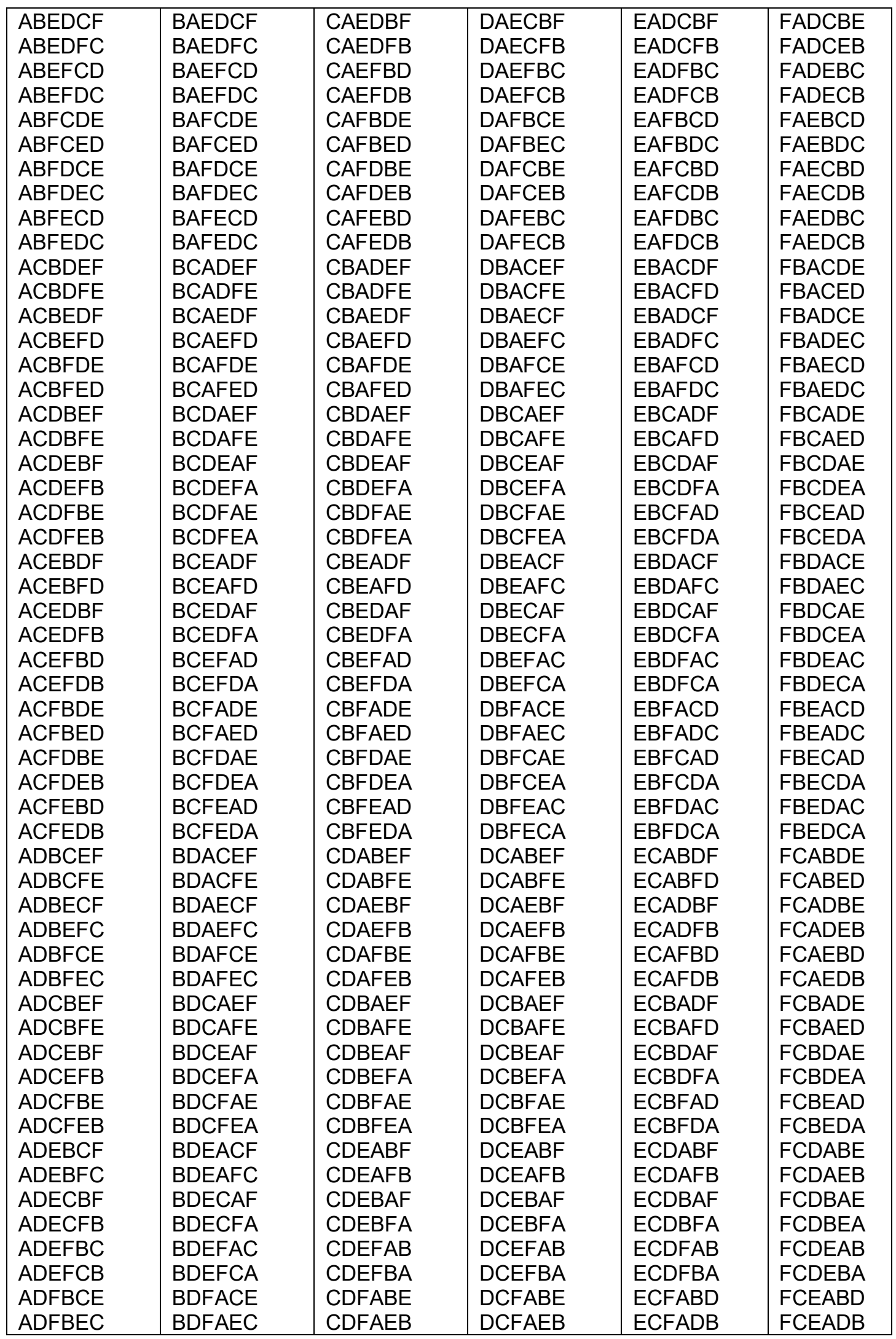


ILKOM Jurnal Ilmiah Volume 9 Nomor 3 Desember 2017

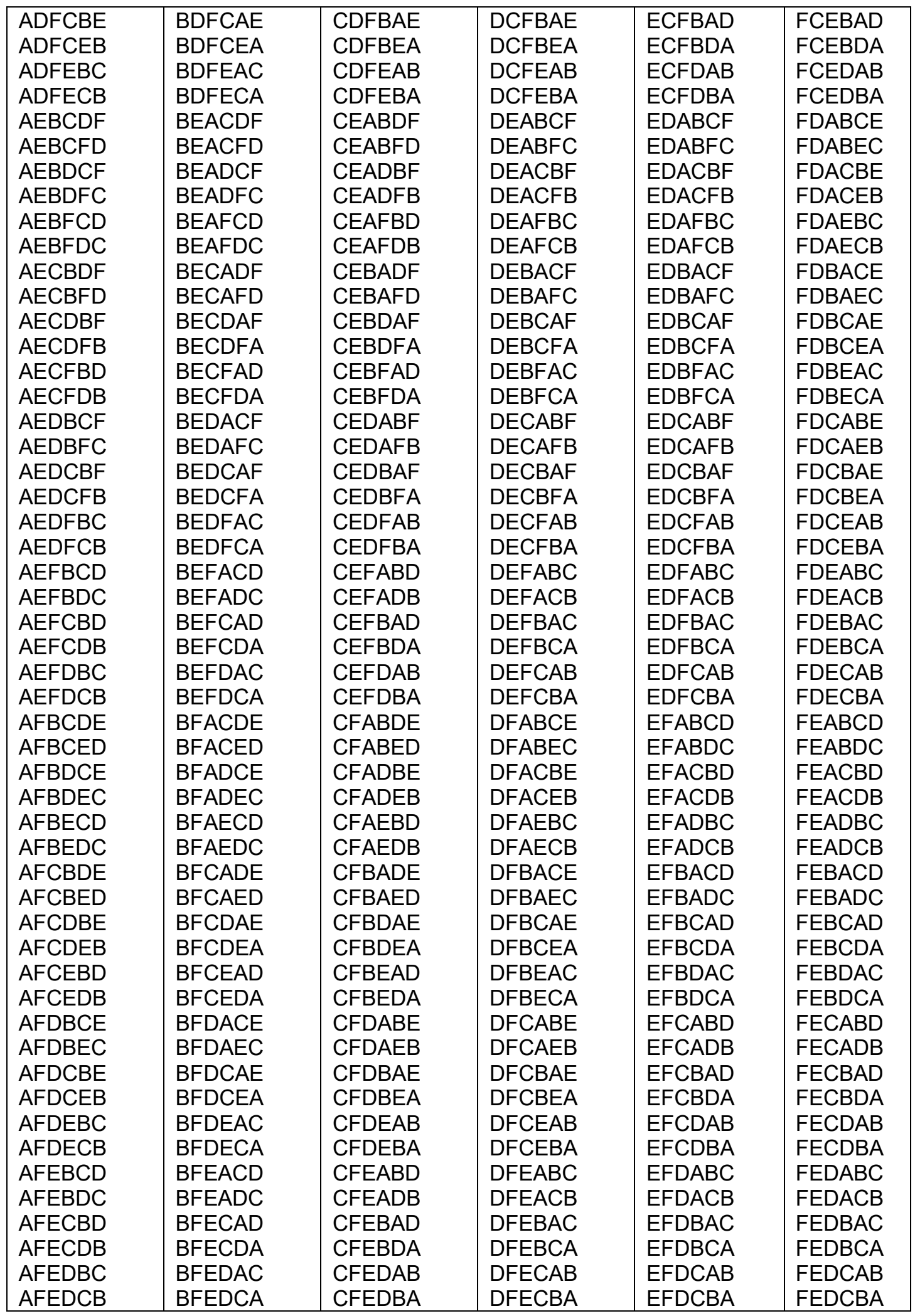




\section{ILKOM Jurnal Ilmiah Volume 9 Nomor 3 Desember 2017}

3. Setelah proses rekursif maka di lakukan proses random untuk menghasilkan tim bermain futsal. Tujuannya adalah untuk menampilkan tim main dalam satu grup dengan cara objektif. Misalkan grup pertama tim bermain futsal hasil random yang tampil adalah ADBECF.

4. Dari hasil random grup pertama kemudian dibagi menjadi dua tim-dua tim, contoh hasil random grup pertama ADBECF jadi A vs D, B vs E, dan C vs F.

5. Lalu menampilkan tim bermain futsal untuk masing-masing grup sebagai acuan panitia dan peserta dalam bermain yang ditampilkan dalam bentuk laporan.

\section{Kesimpulan}

1. Penelitian ini menghasilkan aplikasi untuk menentukan tim yang akan bermain dalam suatu pertandingan. Dengan proses rekursif dalam aplikasi tersebut secara cepat menentukan grup-grup tim yang akan bertanding serta kemungkinan-kemungkinan tim yang akan bertanding, dengan seleksi random yang diberikan dalam aplikasi tersebut, maka dapat menentukan tim bermain futsal yang akan bertanding secara objektif

2. Hasil dari penelitian ini mampu dapat menggantikan sistem pemilihan tim dengan cara manual dengan menggunakan kertas dan mampu mengatasi kesulitan panitia dalam menentukan tim dalam dalam setiap grupnya.

\section{Daftar Pustaka}

[1] Ardianto,Elvinaro.2010.Metodologi penelitian kuantitatif dan kualitatif.

[2] Hasan, M lqbal. 2002. Pokok-pokok Materi Pengambilan Keputusan.

[3] Cresswell,J.W.(1994).Research Design,Qualitative and Quantitative Approaches. London: Sage Publications, Inc.

[4] http://www.indra-update.web.id/2015/04/metode.rekursif.pada.pemrograman.lisp.html diakses pada (24/6/15 jam 10.10).

[5] https://scholar.google.co.id/scholar?hl=id\&q=sistem+pendukung+keputusan +penentuan+tim+bermain +pada+pertandingan+futsal\&btnG diakses pada ( 7.7.15 jam 1.07).

[6] Lhaksana, Justinus. 2011. Taktik dan strategi Futsal Modern. Penebar Swadaya Group.

[7] Munir, Rinaldi. 2007. Algoritma dan Pemrograman. Informatika Bandung.

[8] http://repository.usu.ac.id/bitstream/handle/ 123456789/63243/ Chapter\%20II.pdf? sequence $=4$ \&isAllowed=y diakses pada ( 8.7.15 jam 8.10).

[9] http://abstrak.ta.uns.ac.id/wisuda/upload/k5610059_bab2.pdf diakses pada ( 10.7.15 jam 9.12). 